\title{
CONFLICTO ÉTNICO, GEOPOLÍTICA E IDENTIDAD: EL CASO DE LAS COMUNIDADES MISKITAS DEL RÍO COCO EN NICARAGUA*
}

\author{
Por \\ Frances Kinloch Tijerino**
}

\begin{abstract}
RESUMEN
En la frontera entre Nicaragua y Honduras se encuentra el río Coco o Wangli; en sus riberas dispersos en pequeñas comunidades a lo largo del río habitan los miskitos, grupo indígena ingnorado hasta 1980 , cuando sus territorios se vieron invadidos y envueltos en un conflicto étnico en el que influyó en forma directa una lucha geopolítica entre varias potencias mundiales.
\end{abstract}

\begin{abstract}
The Coco or Wangli River is located on the border between Nicaragua and Honduras. Along its banks, in communities dispersed along the river, live the Miskitos, and indigenous gruop unknown until 1980. At that time their territories were invaded and involved in an ethnic conflict, in which a geopolitical struggle between various world powers had direct influence.
\end{abstract}

\section{INTRODUCCIÓN}

El río Coco o Wangki, tiene una longitud de $780 \mathrm{~km}$ y sirve de línea fronteriza entre Nicaragua y Honduras. En sus riberas habitan unos 35000 miskitos, dispersos en pequeñas comunidades a lo largo del río. Su existencia

* Este artículo se presentó en el evento "Fronteras en pespectiva internacional", efectuado en la Universidad Autónoma de Baja California, los días 17 y 18 de noviembre de 1997. ** Instituto de Historia de Nicaragua y Centroamérica (IHNCA-UCA). 
pasó virtualmente desapercibida para la mayoría de los habitantes de los núcleos urbanos de la costa del Pacífico nicaragüense hasta la década de 1980 , cuando se vieron atrapados en la vorágine de la guerra y desplazados de sus tierras ancestrales hacia asentamientos en el interior de Nicaragua o a campos de refugiados en Honduras. Esta experiencia traumática y dolorosa tiene como trasfondo un conflicto étnico de larga gestación histórica, en el que incidió en forma directa la lucha geopolítica entre diversas potencias.

\section{COLONIZACIÓN DE NICARAGUA POR POTENCIAS RIVALES}

Durante los siglos XVII y XVIII, lo que hoy conocemos como Nicaragua fue el escenario de la disputa hegemónica entre España e Inglaterra. Estas potencias se dividieron el territorio nicaragüense bajo distintas modalidades de colonización.

La conquista española de la región del Pacífico se inició en 1523. Las principales ciudades fueron fundadas en las inmediaciones de pueblos indígenas que tenían una cultura agrícola afín a las de la región mesoamericana. Pronto, éstos fueron diezmados debido a la guerra, las enfermedades y la exportación de esclavos hacia Perú, Panamá y las Antillas. Diversos estudios de demografía histórica estiman la población original de Nicaragua entre 500000 y 800000 indígenas, pero el censo levantado por el gobernador de Nicaragua en 1581 —onsiderado el más exhaustivo del siglo XVI- registra apenas 15694 indígenas. Los estragos de la conquista significaron, pues, una reducción de $97 \%$ de la población aborigen del Pacífico en tan sólo seis décadas. ${ }^{1}$

A inicios del siglo XVI, la llanura costera del Caribe se hallaba habitada por unos 90000 indígenas de origen macro-chibcha que habían emigrado desde el sur, asentándose en pequeñas comunidades a lo largo del litoral o en las cuencas de los ríos. Su principal fuente de subsistencia era la caza, la pesca y la recolección de frutas silvestres. La existencia de una barrera geográfica natural - una cadena montañosa que atraviesa el territorio nicaragüense en dirección noroeste a sureste- obstaculizó la extensión del dominio español hacia la costa atlántica. Por otra parte, el carácter selvático y pantanoso de la región, así como la ausencia de concentraciones

\footnotetext{
1 Ver las obras de Linda Newson, "The Depopulation of Nicaragua in the Sixteenth Century" (1982). Consultar también su libro Indian Survival in Colonial Nicaragua (1987). Los estimados de Newson se sitúan en un punto intermedio entre los cálculos demográficos proporcionados por Radell y McLeod.
} 
significativas de población indígena, hacía poco lucrativa una empresa colonizadora al modo del Pacífico. ${ }^{2}$

La influencia inglesa en la costa atlántica se inició en la década de 1630, a raíz de la fundación de una colonia comercial por puritanos ingleses en la isla de Providencia. En 1634, los colonos construyeron una pequeña fortaleza en el cabo Gracias a Dios, desde la cual intercambiaban con los miskitos herramientas y otros productos ingleses por goma de pino, maderas, plumas y pieles. Los directores de la compañía orientaron expresamente a sus agentes procurarse la simpatía de los indígenas y prohibieron su esclavización. (Parsons, 1956:1-84).

En 1655, la isla de Jamaicacayó en poder de los ingleses y se convirtió en refugio de piratas y bucaneros, quienes encontraron entre los miskitos un importante aliado militar. Participaban con beligerancia en el asalto de caravanas o buques comerciales españoles, así como en el saqueo de las ciudades del Pacífico nicaragüense, utilizando, con frecuencia, la ruta fluvial del río Coco. ${ }^{3}$

En 1687, los ingleses llevaron a uno de los jefes indígenas de la región del cabo Gracias a Dios hasta Jamaica, donde el gobernador le otorgó el título de king. Poco después confirieron el título de governor a otro jefe miskito que habitaba al sur del cabo (entre Sandy Bay y Bragman's Bluff); y el de general a un tercero, quien ejercía su autoridad en la región septentrional de la Mosquitia. ${ }^{4}$

La alianza con los ingleses permitió a los miskitos obtener armas de fuego y cambiar sus pipantes de remo por embarcaciones de vela, con las que empezaron a recorrer todo el litoral desde Yucatán hasta Panamá (Romero Vargas, 1996). En el siglo XVIII, intensificaron sus ataques a los poblados de la región central de Nicaragua, al extremo que el obispo de León suplicó al rey de España que los mandara exterminar.

2 No obstante, Newson estima que las incursiones de expediciones esclavistas y, con ellas, la propagación de mortales epidemias, también causaron estragos entre la población del atlántico, reduciéndola en $50 \%$.

3 La prohibición de la piratería en 1685 y el desarrollo de la plantación azucarera en el Caribe inglés, introdujo la demanda de un nuevo artículo de intercambio: la mano de obra esclava. La superioridad militar de los miskitos, adquirida gracias a su relación con los piratas, les permitió convertirse en suplidores de esa mercancía humana, cazando esclavos entre los otros grupos étnicos de la costa atlántica, en especial, los sumos y ramas.

En 1640, un barco cargado de esclavos africanos naufragó en las cercanías del cabo Gracias a Dios, y los sobrevivientes se mezclaron con los indígenas de esta zona - hecho que dio origen a la distinción entre "zambos-miskitos" e indígenas "puros"- - Estos últimos eran Ilamados Tawiras, vocablo que significa "cabello liso". Hacia mediados del siglo XVII, los cargos otorgados por los ingleses a distintos jefes miskitos se multiplicaron. Surgieron almirantes, coroneles, duques, príncipes y capitanes que empezaron a rivalizar entre sí. En 1787 estalló una cruenta guerra entre el king y el govemor, durante la cual fueron arrasadas aldeas enteras. 
Puesto que se consideraban súbditos de Gran Bretaña, los miskitos asumían como propios los conflictos bélicos entre las metrópolis europeas e identificaban a criollos y mestizos como "españoles". Por su parte, los criollos calificaban a los miskitos de "caribes" (sinónimo de salvajes, paganos y antropófagos). En 1762 y 1780 , el gobernador británico en Jamaica lanzó dos expediciones militares con el propósito de conquistar el territorio nicaragüense, y dividir el imperio español en América. La segunda, al mando de John Polson y Horacio Nelson, contó con una flota de 3000 soldados ingleses, a los que se sumaron 400 miskitos. Aunque los ingleses fueron derrotados por las enfermedades tropicales antes de llegar al interior de la provincia, estos episodios fueron transmutados en épicas heroicas en la memoria colectiva de los criollos y mestizos del Pacífico.

Luego de la independencia de Nicaragua, ocurrida el año de 1821, esta tradición patriótica fue incorporada al discurso nacionalista de los nuevos gobernantes criollos. La percepción de los miskitos como aliados del temible enemigo británico se vio reforzada en 1844, cuando la poderosa Albión anunció oficialmente que el reino mosquito se hallaba bajo su protección, y que sus dominios se extendían desde cabo Camarón en Honduras, hasta Bocas del Toro en Panamá. Esta decisión fue tomada a raíz de que los estudios topográficos de John Baily demostraran la factibilidad de abrir un canal interoceánico aprovechando el gran lago interior de Nicaragua y su desaguadero en el Atlántico (Rodríguez, 1964). Con la creación del protectorado, el estratégico río San Juan quedaba bajo la jurisdicción del rey mosco — quien, naturalmente, se convirtió en blanco de la ira patriótica de los gobernantes criollos del Pacífico.

\section{LA RESERVA MOSQUITIA}

En 1850, Gran Bretaña y Estados Unidos convinieron, mediante el Tratado Clayton-Bulwer, aunar esfuerzos en torno al proyecto canalero y respetar su neutralidad. Asegurados sus intereses comerciales mediante esta alianza, Gran Bretaña volvió los ojos hacia sus dominios asiáticos y puso fin al protectorado. En 1860, reconoció la soberanía de Nicaragua sobre la costa atlántica. A cambio, el gobierno nicaragüense se comprometió a respetar la autonomía de los indígenas dentro de un distrito o reserva, cuyos límites se establecieron entre los ríos Hueso y Rama; es decir, la zona que había estado bajo la jurisdicción del governor antes de $18444^{5}$

5 "Tratado de Managua, entre Nicaragua y la Gran Bretaña, en el que se da por finalizado el protectorado inglés sobre la costa oriental de Nicaragua", zò de enero de 1860. (Encuentro, núm. 24-25; pp. 158-160). 
Paradójicamente, cabo Gracias a Dios — principal zona ecológica y cultural de los miskitos - quedó fuera de la reserva y fue incorporada directamente bajo la autoridad del gobierno nicaragüense, representado por un superintendente originario del Pacífico (Alegret, s/f:65-94). La región al norte del río Coco, tradicionalmente bajo la jurisdicción del general, fue entregada por Gran Bretaña al gobierno de Honduras mediante el Tratado de Comayagua, originando un conflicto limítrofe entre ambos Estados centroamericanos, que perduró hasta 1960.

Los tratados y delimitaciones fronterizas, efectuados a nivel de los Estados, poco afectaban la vida cotidiana de los indígenas del río Coco. Sin embargo, la llegada de misioneros moravos en 1849, sí modificó su cultura y las relaciones de autoridad a lo interno de sus comunidades. A través de una persistente labor pedagógica, realizada en la lengua materna de los indígenas, los misioneros lograron motivar a la población a participar activamente en la vida de sus comunidades, de manera que el liderazgo religioso se fusionó con el liderazgo familiar y comunal (Von Oertzen, Rossbach y Wunderich, 1990:42).

Abandonados por sus protectores británicos en 1860, los miskitos vivían en constante temor de una invasión "española" desde el Pacífico. En este clima de incertidumbre, se produjo un intenso reavivamiento religioso alrededor de la iglesia morava, sobre todo a partir de la década de $1880 .{ }^{6}$ Cabe señalar que la iglesia morava adoptó desde el principio un discurso de rechazo al gobierno nicaragiense, dado que la Constitución de la república establecía el catolicismo como religión oficial.

\section{LA REINCORPORACIÓN Y EL SURGIMIENTO DE UNA ECONOMÍA DE ENCLAVE}

Los temores de los miskitos no tardaron en hacerse realidad. En 1894, en el contexto de la revolución liberal, el presidente José Santos Zelaya, puso fin a la autonomía de la reserva, la ocupó militarmente y la incorporó al Estado en calidad de departamento, al que generosamente le obsequió su nombre. (Rossbach y Wunderich, 1994).

A raíz de la reincorporación, la autoridad máxima en la costa pasó a ser un gobernador intendente designado por el presidente de la república. Éste impuso la ley marcial, prohibió el uso del inglés en las escuelas, y ordenó que toda la enseñanza, así como las transacciones legales, se llevaran a cabo en castellano. La iglesia morava se vio entonces obligada

6 Este fenómeno se repetiría, un siglo después, durante el periodo de cambios acelerados producidos por la revolución sandinista. 
a cerrar gran parte de sus centros docentes durante más de una década (Rodríguez, 1997).

Unos 1800 líderes de las diversas comunidades indígenas enviaron una dramática carta a la reina Victoria, reclamando su protección. Este documento enfatizaba las diferencias entre los miskitos y los "españoles" en cuanto a costumbres, religión, leyes y lengua. Reflejaba, pues, una definición cousciente de su identidad en oposición al grupo étnico que controlaba el aparato estatal desde el Pacífico.

Gran Bretaña desoyó sus súplicas, pero pronto los miskitos identificaron una nueva potencia amiga: en 1909, los Estados Unidos derrocaron al presidente Zelaya, pues el mandatario había cometido la imprudencia de gestionar apoyo alemán y japonés para el proyecto canalero por la ruta del río San Juan, luego de que los estadounidenses habían iniciado ya la construcción del canal por Panamá.

A fin de impedir otro desafío similar a su hegemonía continental, los marines estadounidenses ocuparon Nicaragua durante las siguientes tres décadas. Al retirarse dejaron —como ejército de ocupación sustituto- a la Guardia Nacional. Ésta se convirtió en el pilar de la dictadura somocista que imperó en Nicaragua desde 1936 hasta 1979, con el abierto apoyo de los Estados Unidos, que la consideraba un importante baluarte anticomunista en Centroamérica.

Durante este periodo, se consolidó una economía de enclave en la costa Atlántica de Nicaragua, bajo el control de las grandes empresas estadounidenses en las que trabajaban miles de indígenas a cambio de bonos canjeables por artículos de consumo en las tiendas de las propias compañías.

A partir de 1921 se establecieron en la región cuatro compañías madereras que arrasaron con los bosques de pino de la sabana miskita en tan sólo 40 años. Por esta misma época llegaron también las compañías mineras. En los años cuarenta, Nicaragua llegó a ser uno de los tres mayores productores de oro en América Latina (metal extraído mediante el proceso de cianuración, cuyos desechos eran vertidos en los ríos). Los mineros indígenas que enfermaban de silicosis y tuberculosis eran despedidos sin indemnización. ${ }^{7}$

7 Esta brutal explotación a la que eran sometidos los miskitos y sumos por parte de las compañías mineras extranjeras, fue denunciado en su oportunidad por el religioso Joaquín Matilló Vila, uno de los fundadores del Instituto Indigenista de Nicaragua, creado en la década de 1950. Paradójicamente, Matilló Vila, quien era, al mismo tiempo, funcionario del Ministerio de Educación, alabó "los anhelos del Gobierne " „.cional por redimir al indígena e incorporarlo del todo a la vida cultural y económica de la nación". (Matilló Vila, 1974:10 y 24). 
El pago de la mano de obra con bonos en vez de salarios, y el incumplimiento de las prestaciones sociales debidas a los trabajadores, permitía a las compañías extranjeras extraer grandes ganancias con un mínimo de inversión. Sin embargo, la mayoría de los miskitos no resienten esta sobreexplotación, por el contrario, expresan nostalgia por los años dorados del boom minero y maderero en la costa, y recuerdan con afecto a sus antiguos jefes estadounidenses (actitud que el antropólogo Charles Hale explica por la "anglo-afinidad" de los miskitos).

\section{CASTELLANIZACIÓN Y COOPERATIVISMO}

En 1955, el Ministerio de Educación de Nicaragua - contando con la asesoría de la Unesco- inició el Proyecto Piloto de Educación Fundamental del Río Coco, cuyo primer objetivo era: "Formar conciencia en los habitantes de la zona indígena de los ríos Coco y Cruta y de las zonas rurales adyacentes, para saber participar en la vida cívica y en los grandes ideales de la patria" (Miñano García, 1960:41).

En su informe final, el asesor de la Unesco afirmó haber comprobado que los miskitos no deseaban aprender a leer y escribir en su idioma vernáculo sino en castellano, para poder realizar sus pequeñas transacciones comerciales con los mestizos y blancos que los visitaban. Por tanto, los esfuerzos del proyecto se concentraron en crear numerosos centros de castellanización en las comunidades del río Coco. ${ }^{8}$

En 1960, otro hecho afectó significativamente la vida de los miskitos del río Coco. El Tribunal de La Haya se pronunció sobre el antiguo conflicto fronterizo entre Nicaragua y Honduras, fijando este río -que históricamente había constituido el eje del territorio étnico-cultural de los miskitos-como línea divisoria entre ambos Estados. Nueve comunidades miskitas de la vega norte del río Coco se trasladaron a Nicaragua, atraídos por las promesas del gobiemo de proporcionarles tierras, casas y servicios públicos. (Smutko, 1996:117-118). ${ }^{9}$

\footnotetext{
8 El asesor de la Unesco describió las dificultades enfrentadas debido a que los miskitos eran "apáticos, glaciales e indiferentes", observación que refleja la persistencia de los estereotipos sobre el aborigen americano, elaborados a mediados del siglo XVIII por el pensamiento antropológico ilustrado. (Ver: Miñano García, 1960:108; Gerbi, 1993).

Nietschmann (1989:25) afirma que soldados mestizos del ejército hondureño empezaron a hostilizar a los miskitos que habitaban y cultivaban la ribera norte del Coco. Quemaban sus cosechas y en dos ocasiones realizaron ataques armados de intimidación, obligándolos a trasladarse al territorio nicaragüense. Unos años más tarde - en el contexto de la llamada "Guerra del Futbol", que estalló entre Honduras y El Salvador en julio de 1969- unos 500 miskitos, armados de rifles y escopetas de cacería, decidieron atacar las guarniciones
} 
En la década de 1960, diversos organismos internacionales cobraron presencia en la región del río Coco, e impulsaron proyectos en apoyo a los miskitos que habían sido trasladados desde Honduras a raíz del fallo de la Corte de La Haya. Asimismo, misioneros capuchinos y misioneras de la Orden de Santa Inés, en colaboración con los misioneros moravos dentro del espíritu del ecumenismo del Concilio Vaticano II, promovieron programas de capacitación de líderes comunales y fomentaron la organización de cooperativas agrícolas (Smutko, 1996:115). La metodología utilizada para formar a los líderes comunales estaba inspirada en la propuesta de Paulo Freire: diálogo en problematización para lograr una educación liberadora. ${ }^{10}$

Animados por el Concilio Vaticano II y el documento de Medellín, los misioneros y misioneras trabajaron conscientemente en la construcción de una nueva identidad étnica entre los miskitos, promoviendo la lectura de la Biblia a la luz de sus tradiciones para fortalecer su autoestima. Al igual que en muchas otras comunidades indígenas en América Latina, este proceso estimuló la creación de organizaciones políticas autóctonas para luchar por sus reivindicaciones particulares (Hawley, s/f).

\section{PARTICIPACIÓN MISKITA EN ELECCIONES NACIONALES CONFLICTIVAS}

En 1974, líderes miskitos y sumos crearon Alpromisu (Alianza para el Progreso de Miskitos y Sumos) y empezaron a tener una participación activa en diversas organizaciones del movimiento indigenista internacional. ${ }^{11}$

En las elecciones locales y nacionales celebradas en septiembre de 1974, los dirigentes de Alpromisu lograron ganar las alcaldías de la región del río Coco, así como una diputación en el Congreso Nacional (Hamlin de Zúñiga, 1974). Los miskitos y sumos tenían por primera vez un vocero dentro de una importante institución del Estado nicaragüense. Este hecho abrió grandes expectativas, pues permitiría a Alpromisu obtener personería

fronterizas del ejército hondureño para retomar su territorio. Esta iniciativa rápidamente fue abortada por el gobierno nicaragüense, que no deseaba verse involucrado en el conflicto vecino. Sin embargo, no ha sido posible corroborar esta versión con otras fuentes.

10 Mary Hamlin de Zúñiga, autora del "Programa integral para la formación de líderes en el río Coco. 1970-1974. Informe Final", es una educadora para la salud pública de origen norteamericano y casada con un miskito.

11 Alpromisu participó en la creación del Consejo Mundial de Pueblos Indígenas (CMPI), y uno de sus miembros llegó a ocupar la presidencia del Cons $s^{*} ;$ Regional de Pueblos Indígenas (CORPI) en 1977. 
jurídica, constituirse en contraparte de organismos internacionales, así como recibir y administrar donaciones o préstamos para programas de desarrollo local.

Sin embargo, para la mayoría de los ciudadanos del Pacífico, las elecciones de 1974 no habían sido más que una nueva burla de la familia Somoza para perpetuarse en el poder por más tiempo. El principal partido de oposición, encabezado por el director del diario La prensa, Pedro Joaquín Chamorro, se neg6́ a participar en la contienda electoral, por considerar que no existían condiciones mínimas para impedir un nuevo fraude. La campaña electoral de Anastasio Somoza Debayle - tercer miembro de la dinastía que gobernaba el país desde 1936 gracias al apoyo estadounidense - fue una descarada provocación para sus opositores. Su consigna favorita, desplegada en vallas propagandísticas y calcomanías, era: "Somoza forever".

El 27 de diciembre de 1974, el Frente Sandinista de Liberación Nacional abrió una ofensiva militar, al irrumpir en una fiesta en honor al embajador estadounidense en Managua y mantener como rehenes a 20 altos funcionarios, hasta que Somoza accedió a liberar a numerosos presos políticos así como a transmitir, durante tres días y por todos los medios de comunicación oficial, un mensaje del FSLN convocando al pueblo nicaragüense a la insurrección contra la dictadura.

La feroz represión desatada a raíz de este operativo guerrillero terminó de aislar a la familia Somoza, cuyo desprestigio venía creciendo a la par de su voracidad. Con el robo descarado de una gran parte de la ayuda internacional enviada para socorrer a las víctimas del terremoto que destruyó la capital en 1972, los Somoza habían logrado acumular ya una fortuna calculada en más de 400000000 de dólares. La unidad de los más variados sectores políticos para derrocar a la dictadura quedó sellada en enero de 1978, cuando Pedro Joaquín Chamorro fue asesinado brutalmente por matones contratados por el hijo del dictador.

La ofensiva final vanguardizada por el FSLN (Frente Sandinista de Liberación Nacional) se prolongó desde septiembre de 1978 a julio de 1979. Según datos recabados por el Consejo Económiço y Social de las Naciones Unidas, tan sólo durante este periodo, alrededor de 35000 personas — en su gran mayoría civiles - perdieron la vida, víctimas del indiscriminado bombardeo que la Fuerza Aérea somocista desató sobre las seis principales ciudades del Pacífico y centro del país. A este dramático saldo se suman alrededor de 110000 heridos y mutilados, 40000 huérfanos y 150000 refugiados. El total en pérdidas y daños materiales de la guerra se estimó en 4185000 de dólares (Consejo Económico y Social de las Naciones Unidas, 1979:18-20). 


\section{NACIONALISMO E INDIGENISMO EN LA REVOLUCIÓN SANDINISTA}

La Junta de Gobierno de Reconstrucción Nacional, hegemonizada por el FSLN, enfrentó una tarea monumental. Según datos registrados por la CEPAL en $1977,47.8 \%$ de la tierra cultivable se hallaba concentrada en manos de $0.7 \%$ de la población; $50.3 \%$ de los nicaragüenses no sabía leer ni escribir; solamente había 17 camas de hospital, 5 médicos y 2 enfermeras por cada 10000 habitantes; la tasa de mortalidad infantil era de 120 por cada 1000 niños nacidos vivos; la infraestructura industrial era muy incipiente, limitada a empresas de ensamblaje en zonas francas; la tasa de desempleo, que alcanzaba 33\% de la población en 1977, se había duplicado como resultado de la guerra. Ante esta situación, el FSLN se propuso un programa de modernización acelerada para sacar al país del subdesarrollo.

El sociólogo David Apter, estudioso de los procesos de modernización en países del tercer mundo, describe un tipo de nacionalismo que denomina "sistema movilizador". Apter sostiene que la industrialización y modernización aceleradas exigen una ideología que simbólicamente identifique al individuo con el Estado. Esto puede lograrse mediante la creación de una nueva "religión cívica" que sacraliza las metas económicas y tecnológicas del régimen, permitiendo movilizar a la gente a fin de que asuma sus costos voluntariamente.

Argumenta que las fuentes de estas nuevas "religiones cívicas" se encuentran en las "necesidades" de las nuevas naciones: la consolidación del Estado, la constitución de una autoridad central fuerte, la sustitución de una mentalidad tradicional por una racionalidad económica y la superación de las lealtades étnicas primarias. ${ }^{12}$

Aunque, en general, los historiadores tendemos a recelar de este tipo de explicaciones, pues reducen los procesos sociales a una evolución estructural en la que los actores humanos quedan sobrando, es preciso concederle a Apter que muchos de los rasgos que él identifica como propios de estos "sistemas movilizadores" del tercer mundo estuvieron presentes en la revolución nicaragüense.

La "mística sandinista", que el discurso nacionalista del FSLN logró infundir entre una gran mayoría de los habitantes del Pacífico y centro del país, permitió que en 1980 , un total de 500000 jóvenes se movilizaran en la Cruzada Nacional de Alfabetización "Héroes y Mártires por la Liberación de Nicaragua", y lograran reducir la tasa de analfabetismo a $12 \%$,

${ }^{12}$ Su enfoque es analizado en: Anthony Smith,Theories of Nationalism, (1983). 
en tan sólo cinco meses. Así también, mediante la movilización de decenas de miles de personas organizadas en las Brigadas de las Jornadas Populares de Salud, 1900000 personas fueron vacunadas contra la malaria, 211000 contra la tuberculosis y 205000 contra el sarampión y la polio (flagelo endémico de la niñez nicaragüense que fue erradicado en 1982). Asimismo, en estos primeros años, una mayoría de la población aceptó las severas restricciones en el consumo de artículos importados, impuesto por el gobierno a fin de invertir las divisas en los llamados Proyectos Estratégicos de la Revolución, que prometían asegurar el despegue económico del país en un mediano plazo (Centro de Comunicación Internacional, 1983).

La reacción al programa de la Junta de Gobierno de Reconstrucción Nacional fue muy diferente entre la población del Atlántico. El FSLN era asociado con un episodio ocurrido en 1931, cuando un misionero moravo fue acusado de espía y ejecutado por un grupo de soldados del general Augusto César Sandino, en el contexto de su lucha nacionalista para expulsar a los marines estadounidenses que ocupaban el país desde 1912. En la década de los cincuenta, los pastores moravos -en su mayoría estadounidenses-, difundieron la ideología del anticomunismo entre las comunidades. El triunfo de la revolución cubana fue percibida como una amenaza debido a la propaganda de la Voz de América, que era de los pocos medios de comunicación a los que se tenía acceso en la costa. Más aún, la invasión de bahía de Cochinos fue lanzada desde Puerto Cabezas - principal centro urbano al norte de la Mosquitia- en medio de una ruidosa campaña publicitaria.

Por otra parte, la actividad represiva de la guardia somocista se había circunscrito a las zonas del Pacífico y del centro del país. Muy pocos costeños participaron en el derrocamiento de la dictadura o se identificaron con la ideología antiimperialista del FSLN (Gordon, 1985).

El recelo de los miskitos, comprensible a la luz de estos antecedentes históricos, se agravó debido a una serie de errores cometidos por el gobierno sandinista. El FSLN demandaba la movilización de todos los nicaragüenses en torno a los grandes objetivos de la revolución, y esperaba que los costeños se incorporaran a las mismas organizaciones de masas creadas en el Pacífico (ver Gurdian y Hale, 1985). Los líderes miskitos lograron conservar la estructura organizativa de Alpromisu, aunque cambiaron su nombre por el de Misurasata (que significa "Miskito, Sumo, Rama junto con los Sandinistas").

Pero el conflicto étnico-nacional no tardó en emerger. En 1980, el principal dirigente de Misurasata, Steadman Fagoth, se opuso con beligerancia a que en la costa Atlántica se llevara a cabo la Campaña de Alfabetización en castellano. El gobierno cedió y Misurasata proporcionó las 
brigadas de alfabetizadores en las lenguas indígenas, con lo que logro fortalecer su prestigio y ampliar sus redes de apoyo, incorporando a la organización a los principales líderes de cada comunidad.

En diciembre de 1980, Misurasata aprobó un plan de acción que contenía reivindicaciones de índole político-administrativo sobre un amplio territorio de la costa atlántica, bajo el argumento de que las tierras ancestrales eran de las naciones indígenas. Los órganos de seguridad del Estado recibieron informes de que se preparaba una gran movilización de las comunidades indígenas para luchar por estas demandas, aprovechando las celebraciones que se llevarían a cabo al término de la Cruzada de Alfabetización en Lenguas. El 20 de febrero de 1981, cuatro soldados del ejército sandinista intentaron detener a unos dirigentes de Misurasata en el interior de una iglesia morava. Éstos se resistieron y se desató un tiroteo en el que resultaron muertas ocho personas: cuatro miskitos y los cuatro soldados mestizos. La noticia se difundió rápidamente y muchos jóvenes vinculados a Misurasata se escondieron en la selva. Fagoth fue encarcelado bajo la acusación de haber sido informante de los órganos de seguridad de Somoza, lo que provocó una gran agitación en la costa. En el mes de mayo fue excarcelado bajo el compromiso de colaborar con el gobierno para aplacar el descontento de los miskitos.

Sin embargo, tan pronto como regresó al río Coco, Fagoth se trasladó a Honduras, seguido por unos 3000 miskitos de las comunidades ribereñas. Desde la radio 15 de Septiembre, establecida en territorio hondureño por ex miembros de la guardia somocista, Fagoth demandó la completa autonomía de Yapti Tasba -la nación indígena para la que reclamaba $60 \%$ de la costa atlántica, equivalente a $30 \%$ de todo el territorio del Estado-. Las demandas de autonomía territorial, gobierno independiente y autodeterminación de Yapti Tasba se fundaban en la premisa de que la nación indígena ya existía desde mucho antes que se formara el Estado nicaragüense, pues se remontaba al surgimiento de la monarquía miskita en el siglo XVII.

En el mes de octubre de 1981, un grupo de 65 jóvenes miskitos y sumos recibieron entrenamiento militar de parte de ex miembros de la Guardia somocista y dos instructores argentinos. A fines de noviembre, este grupo conocido como los Astros, cruzó nuevamente la frontera y realizó ataques sorpresivos en contra de pequeñas guarniciones del ejército sandinista en siete comunidades miskitas. Los incidentes militares se sucedieron rápidamente. El 18 de diciembre, los Astros derribaron un helicóptero y dieron muerte a ocho soldados; cuatro días más tarde, el ejército contraatacó dando muerte a 17 miskitos en Leimus (Nietschiıann, 1989:33). Al 31 de diciembre de 1981, 45 miembros del ejército sandinista y 15 civiles habían 
perecido en ataques perpetrados por miskitos y ex guardias somocistas operando en la región del río Coco desde bases en Honduras.

Temeroso de que las comunidades del río Coco se convirtieran en base de apoyo de los alzados en armas, el gobierno sandinista ordenó, el 1 de enero de 1982, el traslado forzoso de aproximadamente 8500 miskitos a cinco asentamientos localizados a unos $80 \mathrm{~km}$ hacia el sur del río, en un área de unas 76000 manzanas de tierra agrícola atravesada por la principal red vial de la región. En su conjunto, los asentamientos recibieron el nombre de Tasba Pri. En este operativo militar, los miskitos presenciaron cómo los soldados sandinistas quemaban sus casas y mataban a sus animales domésticos, para impedir que fueran ocupados por los alzados. En lógica reacción, unos 12000 miskitos cruzaron la frontera y se refugiaron en Honduras. En 1983, se les sumaron 4000 nuevos refugiados, y el siguiente año llegaron 3200 más. (American Watch Committee, 1986).

\section{GEOPOLÍTICA E INDIGENISMO}

El proyecto de autonomía de Yapti Tasba, presentado por Fagoth desde Honduras en julio de 1981, contó con la asesoría de miembros de la organización estadounidense Cultural Survival y con el respaldo de algunas figuras prominentes del mundo académico, como el geógrafo estadounidense doctor Bernard Nietschmann, mejor reconocido por su excelente estudio sobre la ecología de subsistencia de los miskitos, publicado en 1973 (Nietschmann, 1973).

Nietschmann argumentó las razones de su apoyo a este proyecto en un artículo titulado "Geopolitics and the Miskito Nation", que publicó acompañado de una serie de mapas conteniendo su propia visión de Mesoamérica (dividida en siete Estados y 50 naciones indígenas; Nietschmann asigna a estas últimas una importancia geopolítica crucial como muros de contención para frenar el avance del comunismo).

En medio de un curioso discurso - que nos evoca tanto a fray Bartolomé de las Casas como a Ronald Reagan- Nietschmann inserta una severa crítica a los "vaqueros" de la Central de Inteligencia Americana (CIA) por discriminar a los miskitos en el suministro de armamento para combatir al régimen sandinista, en comparación con lo que estaban recibiendo los ex guardias somocistas que operaban desde Honduras (FDN) y el grupo de Edén Pastora (ARDE) que operaba desde Costa Rica (Nietschmann, 1989:39-41).

En efecto, desde 1983, los Estados Unidos empezaron a utilizar la Mosquitia hondureña para efectuar maniobras militares a gran escala. Ese 
año, 16000 soldados estadounidenses y 4000 hondureños, se movilizaron a $40 \mathrm{~km}$ de la frontera con Nicaragua, en un ejercicio militar designado con el nombre de Awas Tara, que en miskito significa "pino grande". Bajo el pretexto de proporcionar una logística adecuada para la realización de estos ejercicios, los Estados Unidos construyeron allí cuatro bases militares y dos aeropuertos. La invasión a Grenada, ocurrida también en 1983, reforzó los temores del régimen sandinista de que estas maniobras eran el preludio de la ocupación estadounidense de una zona de la costa atlántica, para obtener el reconocimiento internacional de los grupos indígenas alzados en armas como una fuerza beligerante y lograr la división del territorio nacional.

Pese a estos temores, el gobierno sandinista se mostró sensible ante las críticas de diversos organismos de defensa de los derechos humanos, y reconoció sus errores en el tratamiento del conflicto étnico-nacional. A fines de 1984, conformó una comisión que elaboró un proyecto de autonomía para la costa atlántica. ${ }^{13}$ Este documento sirvió de base para iniciar negociaciones de paz con el dirigente miskito Brooklin Rivera, pero las partes enfrentaron un desacuerdo esencial en cuanto a la definición de los indígenas y su relación con el Estado. El gobierno reconocía que "los grupos étnicos de la costa atlántica deben gozar de derechos especiales de autonomía que garanticen su identidad étnica y que así debe ser consignado en las leyes de la república con rango constitucional." (Governor of Nicaragua, 1984). Por su parte, los dirigentes miskitos exigían que se les considerara como "pueblos indígenas soberanos [...] en posesión del derecho natural de determinar libremente su propio desarrollo político, económico, social y cultural, de acuerdo a sus valores y tradiciones." (Misurasata, 1984).

Aunque las negociaciones de paz con los dirigentes miskitos se interrumpieron en abril de 1985, el gobierno sandinista dio otra muestra de su voluntad de rectificar los errores cometidos: autorizó el retorno de los miskitos asentados en Tasba Pri y les proporcionó transporte y materiales para reconstruir sus comunidades. En los siguientes meses, unos 14800 miskitos regresaron al río Coco.

\footnotetext{
${ }^{13} \mathrm{El}$ proyecto de autonomía fue incorporado a la Constitución de Nicaragua, y el Departamento de Zelaya se transformó en la Región Autónoma del Atlántico Norte y la Región Autónoma del Atlántico Sur, en las que rigen sendos consejos regionales, integrados por 45 miembros, electos por voto universal, libre y secreto. Las atribuciones de los consejos comprenden: participar en la elaboración y ejecución de los programas y políticas nacionales que conciernan a su región; elaborar el anteproyecto de presupuestr regional en coordinación con el Ministerio de Finanzas; elegir, de entre sus miembros, al coordinador regional, que desempeña funciones ejecutivas.
} 
Esta muestra de buena voluntad no tuvo los efectos deseados. En octubre de 1985 se conformaron dos nuevas organizaciones militares indígenas llamadas Misura y Kisan, que recibieron equipos militares de manos de la Central de Inteligencia Americana (Nietschmann, 1989).

En abril de 1986, en vísperas de una votación crucial en el seno del congreso estadounidense - en la que estaba en juego la suspensión de la ayuda militar a la contra- 6000 miskitos de los que habían regresado al río Coco desde Tasba Pri, se trasladaron hacia los centros de socorro establecidos por Naciones Unidas en Honduras. Este inesperado éxodo se produjo en medio de una gran agitación propagandística convocada por la Embajada de Estados Unidos en ese país. Varias organizaciones pro derechos humanos, que habían mantenido una posición muy crítica contra el FSLN desde 1982, denunciaron ahora al gobierno de los Estados Unidos por utilizar a los miskitos como peones para manipular la opinión del congreso. La maniobra cumplió sus objetivos, pues unos días más tarde, los congresistas otorgaron a la administración Reagan un nuevo paquete de 100000000 de dólares para seguir financiado la "guerra encubierta" en contra del gobierno nicaragüense. (American Watch Committee, 1986).

Mientras tanto, los líderes de Kisan y Misura se habían quejado ante el Departamento de Estado por la ineficiencia de la CIA en el suministro de logística militar. A inicios de 1987 lograron que se les asignara un presupuesto de 5000000 de dólares del paquete global de 100000000 aprobado por el congreso para la contra en 1986. La responsabilidad del manejo de estos fondos se trasladó a la Nicaragua Coordinating Office (NCO) del Departamento de Estado, gracias a lo cual los combatientes indígenas empezaron a recibir buenas armas y equipos en abundancia. Esto les permitió lanzar una serie de ataques alrededor de Puerto Cabezas.

Sin embargo, contrario a las expectativas del Departamento de Estado, el dirigente miskito Brooklin Rivera aprovechó estas victorias militares para entrar nuevamente en negociaciones con el Frente Sandinista desde una posición más fuerte. Esta decisión —que, según Nietschmann, exasperó a los funcionarios norteamericanos- estuvo precedida por la firma del Plan de Paz Centroamericano (Esquipulas II) por parte de todos los presidentes del istmo, el 7 de agosto de 1987. Finalmente, el 2 de febrero de 1988, Brooklin Rivera firmó un acuerdo preliminar de paz con el gobierno sandinista y se comprometió al desarme de sus unidades militares. Ambos acuerdos incidieron en el ánimo de los congresistas estadounidenses y el 3 de febrero rechazaron, por una estrecha mayoría de votos, la solicitud del presidente Reagan de aprobar nuevos fondos para financiar la guerra en contra del gobierno de Nicaragua, eliminando así un poderoso obstáculo para el proceso de pacificación (Nietschmann, 1989). 


\section{IDENTIDAD}

¿Cómo ha incidido este drama en la autopercepción de los miskitos? Entre 1993 y 1994, la antropóloga Claudia García (1997), realizó un interesante trabajo de campo en Asang - comunidad del río Coco que en la década de 1960 fue estudiada por la doctora Mary Helms - con el fin de explorar cómo las experiencias de vida han originado nuevas identidades sociales entre los miskitos. Observó diversos niveles de identidad: algunos tradicionales y otros surgidos en reacción a la historia reciente.

En primer lugar, explica que cada hogar se reconoce como una unidad con los demás hogares de la comunidad con quienes comparte un mismo apellido. Estos conforman los kiamp de Asang, localizados, por lo general, en una misma delimitación espacial por línea materna.

Otra base de referencia identitaria es la unidad socioeconómica conformada por el río Coco. Al presentarse, los miskitos suelen referirse a su comunidad de origen, pero a continuación agregan: "Río Coco". Este hábitat - en el que existe un predominio absoluto del idioma miskito, de la cultura tradicional y la religión morava-constituye también un punto de referencia para diferenciarse de otros grupos miskitos que viven en los centros urbanos de la costa. ${ }^{14}$

Dentro de la misma comunidad, García notó una diferenciación entre los asang y los no asang. La primera categoría incluye tanto a los nacidos allí como a sus descendientes, aun cuando hayan debido ausentarse por algún periodo.

A nivel global y como resultado de las experiencias de los últimos 25 años, García observó la incorporación de elementos procedentes del discurso indigenista panindianista y cuartomundista en la autopercepción de los entrevistados. Al asumirse como "indios", los miskitos de Asang se manifestaron vinculados a las demás poblaciones americanas en una relación común frente al hombre blanco (García, 1997).

Asimismo, el discurso homogeneizante de la revolución sandinista provoco entre los miskitos una reafirmación de sus valores tradicionales, un retorno a prácticas culturales propias y un mayor apego al idioma nativo. Muchas de las creencias transmitidas oralmente de generación en generación han sido revalorizadas.

\footnotetext{
${ }^{14}$ Este fenómeno también fue observado por Nolan, quien explica que los miskitos del río Coco se sienten superiores a los de Puerto Cabezas. Se describen a sí mismos como "productores" para distinguirse de los porteños, a quienes ca'ifican de haraganes que gustan sólo de consumir. (Nolan, 1986).
} 
La apertura a la influencia extranjera, notoria durante el periodo de auge de la economía de enclave, se ha reducido significativamente. García concluye que la tradición, esfera de acción controlada por las mujeres de la comunidad, constituye hoy una importante fuente de autoidentificación del grupo a nivel local. No obstante, la guerra y la desarticulación de las comunidades durante la década de los ochenta, introdujo también un reconocimiento diferenciado, fundado en una nueva serie de oposiciones políticas.

De los 50 hogares entrevistados por García, 24 familias habían sido trasladadas por el gobierno sandinista al reasentamiento de Sumubila, dentro del proyecto de Tasba Pri. Otras 25 familias cruzaron el río en forma voluntaria hacia un campamento de refugiados en Mokorón, Honduras.

A partir de 1986, muchos miskitos de Asang fueron regresando a su comunidad ancestral. Sin embargo, hoy la parte del poblado habitada por los que regresaron de Mokorón se conoce como "Asang-Washington", y a los miskitos que retornaron desde Sumubila se les llama "Asang-Moscow".

García observó que esta nueva diferenciación de bases políticas ha introducido una división entre los kiamp e incluso entre la congregación morava. En la actualidad, la gente se reconoce como "Asang-Washington" o "Asang-Moscow", oponiéndose e identificándose unos a otros de esta manera. Ello refleja los recelos mutuos entre los que estuvieron en Mokorón o en Sumubila, y es frecuente que los primeros acusen a los segundos de sandinistas o satanistas.

Estas nuevas oposiciones internas agregan un obstáculo más en la difícil reconstrucción de las comunidades miskitas en el río Coco, sumidas hoy en una situación de pobreza sin precedentes.

Los datos publicados en 1995 por el Instituto Nicaragüense de Estadísticas y Censos (INEC) sobre la situación socioeconómica de las comunidades del río Coco son dramáticos.

Solamente $5.6 \%$ de las viviendas dispone de energía eléctrica; el suministro de agua potable es aún más bajo: apenas $2.7 \%$ de las viviendas cuentan con este vital servicio; la comunicación telefónica con el resto de Nicaragua es inexistente, y solamente la cabecera municipal tiene una oficina de servicio telegráfico.

La infraestructura del sistema educativo es apenas mejor: en 1994 había 2 escuelas de secundaria y 74 escuelas de enseñanza primaria para las 83 comunidades del municipio (atendidas en su gran mayoría por maestros empíricos, es decir, no preparados formalmente para cumplir esa tarea).

La presencia del sistema nacional de salud es prácticamente simbólica: no existe un hospital en todo el municipio, tan sólo un centro de salud y once puestos de salud para atender a más de 30000 personas dispersas en 
$8000 \mathrm{~km}^{2}$ de territorio. El hospital de Bilwaskarma, construido por li iglesia morava a inicios de siglo, y la clínica fundada por las misioneras de la Orden de Santa Inés en Waspán, fueron destruidos durante la guerra (Rivera, et al., 1996).

Resuelto el conflicto militar con el triunfo electoral de la Unión Nacional Opositora al FSLN, la existencia de los miskitos en el río Coco ha quedado nuevamente en el olvido. Su tragedia pasa desapercibida para los políticos y las agencias gubernamentales.

\section{BIBLIOGRAFÍA}

Americas Watch Committee. 1986. "With the Miskitos in Honduras", abril 11.

ALEGRET, Juan L. s/f. "La comarca de cabo Gracias a Dios: apuntes para su historia”, en: Encuentro, núm. 24-25, pp. 65-94.

Consejo Económico y Social de las Naciones Unidas, 1979. Nicaragua: repercusiones económicas de los acontecimientos políticos recientes. E/CEPAL/G.1091/Rev. 1, diciembre de 1979, pp. 18-20.

GARCÍA, Claudia. 1997. "Diferentes niveles de identificación de la población miskita de Asang, río Coco", en: WANI, núm. 21, Managua: CIDCA, junio/septiembre.

GERBI, Antonello. 1993. La disputa del Nuevo Mundo. Historia de una polémica (1750-1900). México: Fondo de Cultura Económica.

GORDON, Edmund T. 1985. "Etnicidad, Conciencia y Revolución: la cuestión miskito-creole en Nicaragua". Encuentro, núm. 24-25, Managua: Universidad Centroamericana, abril-septiembre.

Government of Nicaragua. 1984. "Draft Agreement", diciembre 8, Bogotá, Colombia. Documento citado en: Diskin, Martin, "El discurso étnico y su desafío a la antropología: el caso nicaragüense", publicado originalmente en inglés en: Urban, G. y Sherzer, J. (eds.) Nation-states and indians in Latin America, University of Texas Press, 1991.

GURDIAN, Galio y Charles Hale. 1985. “¿Integración o participacíon? El Proyecto de autonomía costeña en la revolución popular sandinista." En: Encuentro, núm. 24-25, Managua: Universidad Centromericana, abril-septiembre.

HAMLIN de Zúñiga, Mary. 1974. "Programa integral para la formación de líderes en el río Coco. 1970-1974. ufforme final". Waspan, Nicaragua. 
HAWLEY, Susan, s/f. “'Habla Dios el Idioma Miskito? La Biblia y la identidad etnica entre los Mískitos de Nicaragua", en: Brett, Mark, Ethnicity and the Bible. Citados en: Smutko, 1996, pp. 142 y sigs. MATILLÓ Vila, Joaquín. 1974. "Antropología e indigenismo en Nicaragua", America Central: Indigenismo y antropología social, Tomo I, Costa Rica: CEDAL, pp. 10 y 24.

MIÑANO García, Max. (Asesor Técnico de la Unesco). 1960. "Proyecto piloto de educación fundamental del río Coco. Informe final". Managua: Ministerio de Educación Pública, p. 41.

Misurasata. 1984. "Draft Agreement", diciembre 8. Bogotá, Colombia, Citado en Diskin 1991.

NEWSON, Linda. 1982. "The Depopulation of Nicaragua in the Sixteenth Century", en: Journal of Latin American Studies, (14)(2):253-268. Cambridge University Press, 1982.

- 1987. Indian Survival in Colonial Nicaragua, University of Oklahoma Press.

NIETSCHMANN, Bernard. 1973. Between Land and Water: The Subsistence Ecology of the Miskito Indians, Eastern Nicargua, Nueva York: Seminar Press.

- 1989. "Geopolitics and the Miskito Nation", The Unknown War: the Miskito Nation, Nicaragua and the United States. University Press of América, p. 25.

NOLAN, Kerri-Anne. 1986. "Problems of Adaptation to Relocation. The Case of Nicaragua's Miskito Indians", Tesis de Maestría inédita, Universidad de Florida.

PARSONS, J.J. 1956. San Andrés y Providencia, University of California, publications in Geography, vol. 12., núm. 1, Berkeley, pp. 1-84. (Citado en Vilas, Carlos. 1992. Estado, clase y etnicidad. La Costa Atlántica de Nicaragua, México, FCE, p. 54).

RIVERA, Virgilio, etal. 1996. Autonomía y sociedad en la RAAN, Managua: CIDCA-UCA.

RODRÍGUEZ, Isolda. 1997. "La educación asimiladora en la Costa Atlántica de Nicaragua", ponencia inédita, Seminario internacional sobre política, cultura y sociedad, Instituto de Historia de Nicaragua y Centroamérica, septiembre.

RODRÍGUEZ, Mario, A 1964. Palmerstonian Diplomat in Central America. Frederick, Esq., Tucson, EEUU: The University of Arizona Press.

ROMERO Vargas, Germán. 1996. Historia de la Costa Atlántica, Managua: CIDCA. 
ROSSBACH, Lioba y Volker Wunderich. 1994. "Derechos indígenas y Estado nacional en Nicaragua: La convención mosquita de 1894", en: Taller de historia, núm. 6, Managua: Instituto de Historia de Nicaragua.

SMITH, Anthony. 1983. Theories of Nationalism, Nueva York: Holmes and Meier Publishers (2nd. ed.), cap. I.

SMUTKO, Fray Gregorio. 1996. La presencia capuchina entre los miskitos (1915-1995), Costa Rica, Imprenta A.G. Covao, pp. 117-118.

VON Oertzen, Eleonere, Lioba Rossbach y Volker Wunderich. 1990. The Nicaraguan Mosquitia in Historical Documents. 1844-1927; the Dynamics of Ethnic and Regional History, Berlin: Reimer, pp. 42. 